\title{
T Cell Mediated Pathogenesis in EAE: Molecular Mechanisms
}

\author{
Florian C. Kurschus
}

\begin{abstract}
$\mathrm{T}$ cells are major initiators and mediators of disease in multiple sclerosis (MS) and in its animal model experimental autoimmune encephalomyelitis (EAE). EAE is an antigen-driven autoimmune model in which immunization against myelin autoantigens elicits strong $\mathrm{T}$ cell responses which initiate its pathology with CNS myelin destruction. T cells cause pathogenic events by several mechanisms; some work in a direct fashion in the CNS, such as direct cytokine-induced damage, granzyme-mediated killing, or glutamate-induced neurotoxicity, whereas most are indirect mechanisms, such as activation of other cell types like macrophages, B cells, or neutrophils. This review aims to describe and discuss the molecular effector mechanism by which T cells harm the CNS during EAE. (Biomed J 2015;38:183-193)
\end{abstract}

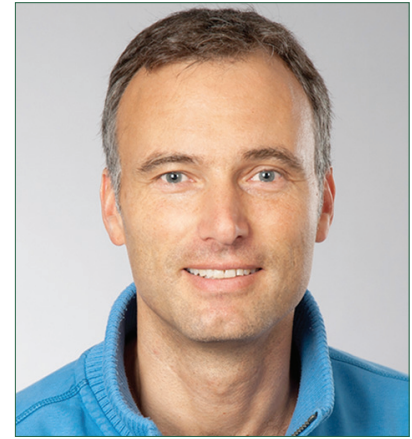

Dr. Florian C. Kurschus

\section{Key words: cytokines, CNS, EAE, multiple sclerosis, $\mathrm{T}$ cells}

\section{EAE - What is it?}

$\mathrm{W}$ hen seen in its entirety, the animal model experimental autoimmune encephalomyelitis (EAE) bears significant similarities to multiple sclerosis (MS) and its different varieties. Depending on the model used, EAE may develop in highly distinct forms such as acute, relapsing-remitting, and primary or even secondary progressive. Although the model was discovered and developed already in the $1930 \mathrm{~s},{ }^{[1]}$ it was only in the 1980s that it was clearly proven that $\mathrm{T}$ cells are the major driver of disease when mice are immunized by CNS antigen in complete Freund's adjuvant (CFA). The major evidence came from adoptive transfer experiments using $\mathrm{T}$ cell lines in rats and mice. ${ }^{[2-5]}$ Even though many similarities are observed between MS and its animal model, major concerns still exist about the etiology and the mechanism (s) of disease development of MS. For example, the autoimmune etiology of MS is still questioned and some researches claim that infections with, for example, Epstein-Barr virus, may play an important role in MS immunopathology. ${ }^{[6,7]}$ Others suggested for some subforms of MS, a primary degenerative scenario with immune-mediated damage playing a secondary role in the disease..$^{[8-12]}$ Also, the composition of CNS-infiltrating cell types differs between EAE and MS; for example, CD8 ${ }^{+}$ T cells, which may be seen as the dominating T cell population in MS histology, ${ }^{[13,14]}$ are not essential for EAE. ${ }^{[15]}$ Another difference might be the presence and the role of neutrophils in MS versus EAE, with EAE being dependent on neutrophils whereas MS seems to lack a clear association with neutrophils. Still, it needs to be emphasized that the pathogenesis in the induced EAE model (but not in spontaneous models) is time wise well controlled and the effect of a certain cellular population can be effectively observed and tested, whereas in MS the timing of the immune response is out of sight and can only be observed during or after acute attacks when the role of populations such as neutrophils may already be blunted. ${ }^{[16]}$

In the standard model most frequently used, EAE is induced by immunization using a water-in-oil emulsion of CFA into which the autoantigen such as myelin oligodendrocyte glycoprotein (MOG), myelin basic protein (MBP), or proteolipid protein (PLP) is mixed. CFA contains high amounts of heat-inactivated Mycobacterium tuberculosis. This emulsion is usually injected subcutaneously in the back skin next to the tail base. Also, pertussis toxin injections are given the same day and 2 days later intraperitoneally. EAE normally develops after about 10 days when scores with ascending paralysis usually become visible.

\section{$T$ cells in EAE}

T cell differentiation is highly influenced and dependent on the cytokine milieu present in the draining lymph nodes

From the Institute for Molecular Medicine, University Medical Center of the Johannes Gutenberg-University Mainz, Mainz, Germany Received: Nov. 28, 2014; Accepted: Mar. 6, 2015

Correspondence to: Dr. Florian C. Kurschus, Institute for Molecular Medicine, University Medical Center of the Johannes

Gutenberg-University Mainz, Germany. Obere Zahlbacher St. 67 D-55131 Mainz, Germany. Tel: 49-6131-179209; Fax: 49-6131-179039;

E-mail: kurschus@uni-mainz.de

DOI: $10.4103 / 2319-4170.155590$ 
during $\mathrm{T}$ cell receptor (TCR) stimulation. In infections, the type of cytokines that are induced is determined by the type of the infectious agent. Sensing of this is realized by antigen presenting cells (APCs) or also directly by the $\mathrm{T}$ cells via toll-like receptors (TLRs) activated by distinct pathogen-associated molecular patterns (PAMPs) produced by the invaders. ${ }^{[17,18]}$ Therefore, the use of $M$. tuberculosis in CFA provides a clear bias to a specific immune response, namely, the one $\mathrm{T}$ cells normally initiate in tuberculosis infection to which differentiation to Th1 or Th17 cells (see below) also belongs. Thereby, the pathway by which autoimmunity is elicited, either by active induction or by creation of TCR transgenic animals, may subvert the type of immune response and the associated molecular mechanisms leading to disease. Also, the type of antigen, or rather the exact epitope used for immunization, was shown to govern the response type and also the disease pattern in EAE. Certain antigens elicit a predominant Th17 and cerebellar disease, while other antigens evoke a mixed Th1/Th17 response with typical lumbar inflammation. ${ }^{[19]}$

EAE, when induced using CFA, is, in the majority of cases, a CD4 ${ }^{+} \mathrm{T}$ helper cell-mediated disease. There are some $\mathrm{CD} 8^{+} \mathrm{T}$ cell-mediated EAE models (see below), though the major culprit in inducing cytotoxic $\mathrm{T}$ cell responses is the use of CFA as it funnels in the typical major histocompatibility class (MHC) class II presentation pathway of APCs for T cell activation. Since the discovery of distinct $\mathrm{T}$ helper subpopulations in the late 1980s by Mossman and Coffman, ${ }^{[20]} \mathrm{EAE}$ was thought to be a prototypical Th1 autoimmune disease due to its strong association with interferon-gamma (IFN- $\gamma$ ) secreting T cells found in the CNS. ${ }^{[21,22]}$ Findings with transferred TCR transgenic Th2 cells eliciting an allergic form of EAE already perturbed this picture ${ }^{[23]} \mathrm{A}$ further challenge to a Th1 view of EAE was the reports published in the 1990s showing that mice deficient for IFN- $\gamma,{ }^{[24]}$ its receptor ${ }^{[25]}$ or the cytokine subunit interleukin (IL)-12-p35 (necessary for Th1 cell differentiation) ${ }^{[26,27]}$ or the IL-12 specific receptor subunit IL-12R $\beta 2^{[28]}$ developed normal or even stronger progression of EAE than their wild-type (WT) control animals. It was soon shown that this discrepancy was due to another form of an immune response, namely, the IL-23/ Th17 axis. ${ }^{[29-31]}$ It turned out that the major important immune response of $\mathrm{T}$ cells in EAE was not Th1 but was dominated by $\mathrm{T}$ helper cells producing IL-17 (IL-17A and IL-17F) after immunization. These Th17 cells are now considered the initiators of disease in the standard EAE model. Th17 cells need external IL-23 and the master transcription factors retinoid-related orphan receptor gamma t $(\mathrm{ROR} \gamma \mathrm{t})^{[32]}$ as well as $\operatorname{ROR} \alpha{ }^{\left[{ }^{[33]}\right.}$ These cells were later shown to switch their phenotype and co-produce IFN- $\gamma$ and granulocyte macrophage-colony stimulating factor (GM-CSF) and, for a major part, also lose the expression of IL-17 in the
CNS completely. ${ }^{[34,35]}$ The latter finding also explains why EAE was seen initially as a Th1 disease. Many experts in this field see such multi-cytokine-producing cells as most pathogenic, especially since co-expression of the Th1 master transcription factor Tbet was shown to be mandatory for the encephalogenicity of Th17 cells. ${ }^{[36]}$ The Th17 supportive cytokine IL-23 was indeed shown to induce Tbet expression in Th17 cells, ${ }^{[35,37]}$ but the role of IFN- $\gamma$ production by Th1/Th17 cells remains elusive. IFN- $\gamma$ is a pleiotropic cytokine with potent immune-stimulating features and, on the other hand, with immune-suppressing features. These include containment of T cell expansion, ${ }^{[38]}$ suppression of

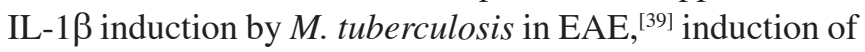
T regulatory (Treg) cells, ${ }^{[40]}$ and induction of multiple immunosuppressive secondary molecules such as Indoleamine 2,3-dioxygenase (IDO) ${ }^{[41]}$ or Programmed death-ligand 1 (PD-L1). ${ }^{[42]}$

\section{T helper cells - How do they do it?}

As described above, the autoantigen-containing CFA emulsion needs to be taken up by endocytosis from APCs. This pathway is luminal and not cytosolic; therefore, most of the injected antigen will be loaded on MHC class II in the endolysosomal MIIC compartment. A further bias for the $\mathrm{CD} 4^{+} \mathrm{T}$ cell induction by contemporary protocols (e.g., MOG peptide 35-55) is that these are long peptides which contain immunodominant epitopes defined for binding to MHC class II molecules. These peptides then stimulate autoantigen-specific $\mathrm{T}$ cells that escaped thymic negative selection. $\mathrm{CD}^{+}$effector $\mathrm{T}$ cells that are commonly induced in EAE start with the expression of IL-17 in the lymph nodes. Some days later, already in the lymph nodes, plasticity of these Th17 cells, which is driven by IL-23, ${ }^{[35]}$ initiates the multi-cytokine program with co-expression of ROR $\gamma t$ and Tbet. Finally in the CNS, effector T cells are found to express either IL-17 or IFN- $\gamma$ or GM-CSF or combinations of all these three cytokines [Figure 1]. ${ }^{[34,35,43]}$

As pointed out earlier, most EAE models are primarily based on activation of encephalitogenic $\mathrm{CD} 4^{+} \mathrm{T}$ helper cells. Their major mechanism is to govern the response mechanism of other cells by secreting cytokines and by direct interaction with these cells via CD40L-CD40 interaction. ${ }^{[44-46]}$ Cytokines are very interesting molecules, most of them acting by distinct so-called Janus kinase (JAK)/Signal Transducer and Activator of Transcription (STAT) pathways. Although activation of the STATs can be measured by phosphostaining, the type of responses induced by cytokines is hard to predict. Most cytokines act in minute amounts, and can elicit robust and also dangerous responses. Therefore, their expression and secretion is highly regulated. 


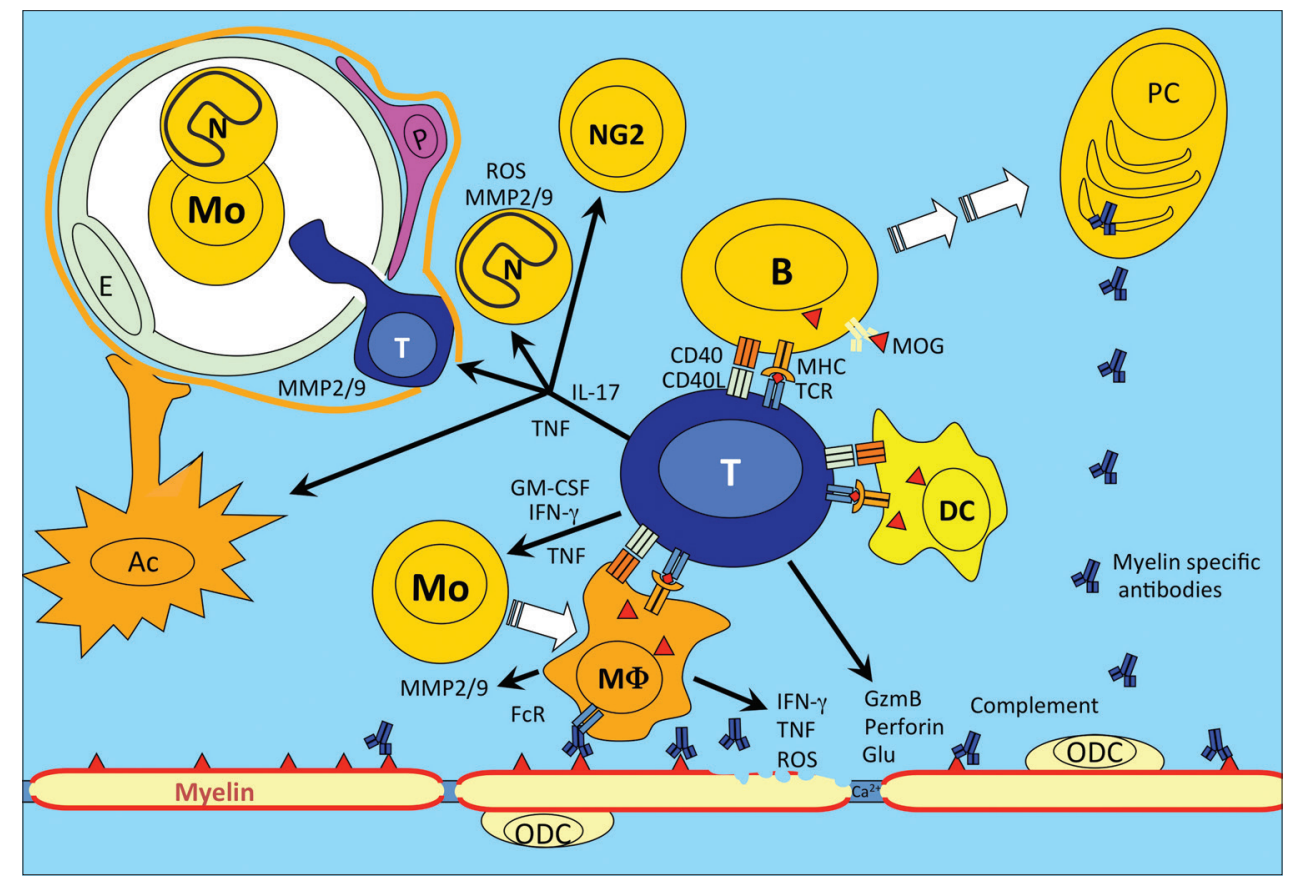

Figure 1: T cell effector mechanisms in EAE. T cells enter the CNS via postcapillary venules and have to cross the blood brain barrier, composed of endothelial cells, the basement membrane, and the parenchymal basement membrane of the glia limitans. ${ }^{[137]}$ They often accumulate in the perivascular space between the two basement membranes. Penetration of the parenchymal basement membrane is facilitated by matrix metalloproteases (MMP2 and MMP9) secreted by T cells, macrophages, and neutrophils. T cells in the CNS are reactivated by macrophages, DCs, and B cells presenting myelin autoantigens and secrete, among others, the cytokines IL-17, IFN- $\gamma$, TNF and GM-CSF. IL-17 induces secondary cytokines, chemokines and MMPs, which help in the breakdown of BBB and in the attraction of monocytes and neutrophils. GM-CSF (together with G-CSF) has long-distance effects on neutrophil mobilization, but possibly also has direct influences on inflammatory monocytes and their capacity to polarize T helper cell differentiation. It probably works additionally by inhibiting Treg function via IL-6 induction in myeloid cells. Cytokines secreted by T cells also influence astrocytes and oligodendrocyte precursor cells (NG2 cells) in their differentiation and in their proliferation capacity. ${ }^{[138]}$ IFN- $\gamma$ and TNF may have direct toxic effects on ODC, but most of all stimulate myeloid effector cells such as inflammatory monocytes, macrophages, and neutrophils. Stimulation of these cells leads to damage of myelin by the secreted reactive oxygen species followed by myelin attack and ingestion by macrophages. Macrophages are also activated by antibodies bound to myelin via FC receptors and by the complement products activated by these antibodies. Myelin-specific antibodies may be released from antibodysecreting plasma cells or plasma blasts originating from myelin-specific B cells activated by T cells in the CNS or in peripheral lymph nodes. Th17 cells damage axons also directly by secretion of glutamate, whereas cytotoxic $\mathrm{CD} 8^{+} \mathrm{T}$ cells secrete perforin, granzymes, and IFN- $\gamma$ to directly attack ODCs. Abbreviations: E: Endothelial cell; P: Pericyte; T: T cell; B: B cell; PC: Plasma cell; Mo: Monocyte; Ac: Astrocyte; N: Neutrophil, MФ: Macrophage; ODC: Myelin forming oligodendrocyte; DC: Dendritic cell; ROS: Reactive oxygen species.

\section{Early infiltration - Th17 cells}

T cell infiltration into the CNS occurs around day 8 or 9, and these T cells mostly express IL-17. ${ }^{[47]}$ The IL-17 family is composed of six members, IL-17A-F ${ }^{[48]}$ that belong to the cysteine knot family. They are structurally unrelated to other cytokines, but have distant similarities to neurotrophins. ${ }^{[49]} \mathrm{IL}-17 \mathrm{~A}, \mathrm{~F}$, and C signal by a unique pathway, utilizing NF- $\mathrm{KB}$ activator 1 (ACT1)/tumor necrosis factor receptor associated factor (TRAF) $6,{ }^{[50,51]}$ with nuclear factor kappa-light-chain-enhancer of activated B cells (NF- $\kappa B$ ) playing an important role as the downstream pathway. ${ }^{[50,52]}$ Of the IL-17 family, IL-17A and IL-17F are the most highly related with about $50 \%$ amino acid sequence identity. ${ }^{[33]}$ They are thought to mediate highly similar responses in target tissues. IL-17C is secreted directly by the epithelial tissue cells ${ }^{[54]}$ and signals very similar to IL-17A/F. ${ }^{[54,55]}$ The cytokines IL-17A and IL-17F are secreted by activated $\alpha \beta$ CD4+ $\mathrm{T}$ cells $(\mathrm{Th} 17),{ }^{[56]} \gamma \delta \mathrm{T}$ cells, ${ }^{[57]}$ natural killer (NK) $\mathrm{T}$ cells, ${ }^{[58]}$ lymphoid tissue inducer cells, ${ }^{[59]}$ and innate lymphoid cells type 3 (ILC3) subsets. ${ }^{[60]}$ Furthermore, IL-17 was shown to be also expressed by mast cells ${ }^{[16]}$ and neutrophils. ${ }^{[62-64]} \mathrm{IL}-7 \mathrm{~A} / \mathrm{F}$ acts mostly on the tissue cells by signaling via the heterodimeric IL-17 receptor composed of IL-17RA ${ }^{[65]}$ and IL-17RC. ${ }^{[66,67]}$ The action of IL-17 is manifold, as it was shown to induce the secretion of matrix metalloproteases (MMP1, MMP3, MMP9, MMP12, and MMP13) and cytokines like GM-CSF, IL-6, and a bunch of chemokines (CCL2, CCL7, CCL20, CXCL1, CXCL2, and CXCL5) by local tissue cells. This cocktail is thought to prepare the tissue and attract further T cells and myeloid 
cell populations into the developing CNS lesion. IL-17 probably also acts directly on the blood-brain barrier (BBB) integrity by induction of reactive oxygen species (ROS) in endothelial cells. ${ }^{[68]}$ IL-17 was also shown to induce downstream mediators of angiogenesis in rheumatoid arthritis and tumor models and in psoriasis. ${ }^{[69-71]}$ Lack of IL-17 signaling hindered efficient erythema formation, which is a typical feature of imiquimod-induced dermatitis, a mouse model for psoriasis. ${ }^{[72]}$ Some of its downstream cytokines, such as granulocyte-colony stimulating factor (G-CSF) and GM-CSF, also have long-distance effects like neutrophil mobilization, as also observed in EAE. Therefore, a major role of IL-17, at least in mice, is to attract the neutrophils into the CNS and activate the latter. ${ }^{[73]}$ This probably occurs rather indirectly by secondary cytokines and chemokines induced by IL-17A together with tumor necrosis factor (TNF) or other cytokines such as IL-1 $\beta$ or IL-22. Recently, it was shown that the neutrophils express the IL-17RA and IL-17RC chains ${ }^{[62]}$ and can react directly with IL-17 in an autocrine manner. Neutrophils enter the CNS early in disease. ${ }^{[74,75]}$ Depletion of neutrophils or blockade of CXCR2, the main chemokine receptor for CXCL1/2 on the neutrophils, inhibited BBB breakdown and EAE manifestation, induced either actively or passively via transfer of myelin-specific T cells..$^{[76,77]}$ The actual role neutrophils play in the CNS is not yet clarified, but they were shown to contribute to destruction of the BBB ${ }^{[78]}$ Furthermore, it was recently shown that neutrophils play an important part in maturation of local APCs in the CNS. ${ }^{[79]}$ Other target cells of IL-17 in the CNS may be the NG2-expressing oligodendrocyte precursor cells. Deletion of the IL-17 signaling molecule ACT1 in these cells was shown to have a major impact on EAE ${ }^{[80]}$ Since ACT1 may be activated by other pathways also, these experiments did not prove that NG2 cells are, indeed, the targets of IL-17 in EAE. Chemokines induced by IL-17 can also attract other cell types such as monocytes and other T cells to perpetuate the initial inflammation. IL-17 acts mostly in synergy with TNF or with IL-22, both cytokines, which are also expressed by infiltrating Th17 cells in $\mathrm{MOG}_{35-55}$-induced EAE. IL-22, which is co-produced not only by Th17 but also by Th1 cells, does not seem to play a major role in EAE, as the knockout mice did not show a change in EAE course compared to WT controls. ${ }^{[81]}$ There might be some hint though that its function may rather be protective in EAE and MS, as the mice deficient for the IL-22 scavenger protein IL-22BP develop lower EAE than WT controls. ${ }^{[82]}$ Interestingly, variants of IL-22BP were independently described as risk factor in MS and EAE. ${ }^{[83,84]}$

Although IL-17 bears all these important functions, it must be pointed out that IL-17 is not absolutely mandatory for active EAE induction, as IL-17RA ${ }^{[85]}$ and IL-17RC knockout animals still develop some residual disease ${ }^{[66]}$ (and our unpublished data) and mice which lack IL-17F and are treated with neutralizing antibody against IL-17A remain susceptible to EAE induction. ${ }^{[86]}$ Further indication for this is that mice lacking ROR $\gamma \mathrm{t}$ are only partially resistant to $\mathrm{EAE},,^{[32,33]}$ as some mice even develop a very strong pathology with a delayed kinetic (our unpublished data). Furthermore, small interfering RNA (siRNA)-mediated ${ }^{[87]}$ or pharmacological inhibition of ROR $\gamma t$ up to now, in most cases, failed to fully inhibit EAE, showing rather a shift in disease onset ${ }^{[88-90]}$ (and our unpublished observations). In summary, the major function of IL-17 may be to allow initial entry of myeloid cells. In the absence of IL-17, other cytokines or $\mathrm{T}$ cell populations may suffice to induce a delayed form of the disease, though with a lower incidence.

\section{What are IL-23 and GM-CSF doing?}

The enigma originated by the findings that $\mathrm{T}$ cells $n$ either needed IL-17 nor IFN- $\gamma$ to induce EAE, leaving the question about the effector mechanism of T cells to induce pathology. It was known that the cytokine which instructs T cells and cannot be replaced in EAE induction is IL-23. But which T cell effector mechanism downstream of IL-23 is the important one? In 2011, two groups independently reported that GM-CSF secreted by T cells is a cytokine induced by IL-23 in T cells and is the irre placeable cytokine of T cells in EAE.$^{[43,91]}$ Although the proof for whether the major task of IL-23 is to induce GM-CSF in T cells is still lacking, namely, transgenic overexpression of GM-CSF specifically in T cells of mice which are deficient for IL-23, these findings were a major step forward and may lead to new treatment options in the future. The question of how GM-CSF, indeed, performs its task is still an enigma. It seems not to influence the number of inflammatory dendritic cells (DCs) in the CNS in EAE,${ }^{[92,93]}$ but may rather influence the polarization capacity of monocyte-derived DCs for $\mathrm{T}$ cells to differentiate into Th17 cells in EAE. This was recently shown by depletion of C-C chemokine receptor type 2 (CCR 2)-positive monocyte-derived DCs ${ }^{[93]}$ Together with the earlier reports, this would fall back again on the IL-17 cytokine. Therefore, probably other mechanisms of IL-23, besides GM-CSF and IL-17 induction, may also play a role in EAE. Alternatively, GM-CSF itself may work by inhibition of Tregs via induction of IL- ${ }^{[94]}$ (another irreplaceable cytokine in EAE) ${ }^{[95]}$ Finally, GM-CSF may play different roles during the peripheral priming phase and in the effector phase in the CNS.

\section{T cells activate macrophages in EAE}

Macrophages play several roles in the pathogenesis of EAE. First, they act by destroying the parenchymal basement membrane formed by astrocytes in the BBB through secretion of matrix metalloproteases (MMP2 and MMP9) ${ }^{[96]}$ which allow leukocytes to leave the perivascular space and 
infiltrate the CNS parenchyma. Second, macrophages damage myelin efficiently by ROS generation. ${ }^{[97,98]}$ In EAE and MS lesions, macrophages have been observed to take up large parts of myelin. ${ }^{[99]} \mathrm{T}$ cells do activate this process by direct interaction with the macrophages and by the cytokines IFN- $\gamma$ and TNF. Macrophage expression of Fc receptors may also be important in mediating the pathogenic effects by autoantibodies in the CNS in EAE. For a long time, it was not really clear whether microglia cells in the CNS become activated in EAE and perform the same duties as macrophages differentiating from infiltrating monocytes. Recently, the group of Ransohoff demonstrated by serial block-face scanning electron microscopy that monocyte-derived macrophages are the cells initiating demyelination at the nodes of Ranvier, whereas microglia were rather found as cells clearing the debris. ${ }^{[100]}$

\section{T cells in spontaneous EAE models}

As described above, the standard model of EAE is induced by peptide or protein immunization. Some TCR transgenic mouse strains bearing TCRs for specific myelin autoantigens develop spontaneous demyelinating disease. This was first found by Goverman et al. under animal housing conditions which were less microbial controlled than the standard specific pathogen free (SPF) conditions. ${ }^{[101]}$ Also, other TCR transgenic strains develop spontaneous EAE, but mostly with high incidence only in the recombination-activating gene (RAG) knockout background, ${ }^{[102]}$ presumably due to lack of efficient Treg development in these animals. ${ }^{[103]}$ One strain, the RR mouse on the SJL/J background, also developed EAE with high incidence in normal housing condition without crossing to the RAG knockout background. ${ }^{[104]}$ TCR transgenic T cells in these animals activate MOG-recognizing B cells of the endogenous repertoire very early in life. These mice, therefore, develop EAE with high MOG-specific antibody titers which are complement fixing. Early depletion of B cells in these animals prevented plasma cell development and antibody titer formation, and ultimately EAE pathogenesis. This model is dependent on B cells and pathogenic antibodies, whereas another spontaneous model of EAE with Devic-like disease, in which $2 \mathrm{D} 2$ mice $^{[105]}$ were crossed with BCR transgenic $\mathrm{IgH}^{\mathrm{MOG}}$ mice ${ }^{[106]}$ (both recognizing MOG epitopes), has been observed not to depend on antibodies. ${ }^{[105,107-109]}$ Here, B cells probably act rather as efficient APCs and cytokine producers for pathogenic $\mathrm{T}$ cell development, reminiscent of the situation in MS where depletion of B cells by Rituximab (an anti-CD20 monoclonal antibody) also shows a beneficial effect independent of the plasma antibody levels found. ${ }^{[110]}$ Molecular interactions in these B cell-antibody dependent models probably occur via TCR/MHCII and CD40L-CD40, as well as by the cytokines produced from $\mathrm{T}$ cells. In the RR model, intra-CNS antibody secretion, presumably by plasma cells, can be observed. This shows similarities to the follicular structures described in the meninges of MS patients. ${ }^{[111]}$ Despite the lack of CFA usage in these spontaneous models, T cells in the CNS express IL-17 and/or IFN- $\gamma$, similar to that in the induced EAE models. Nevertheless, one has to keep in mind that the TCRs used in these models descend from $\mathrm{T}$ cells of mice previously immunized against myelin antigens.

\section{Direct mechanisms of damage by $\mathrm{T}$ helper cells?}

One of the rare direct mechanisms through which Thelper cells act in EAE pathology was recently demonstrated. ${ }^{[12]}$ Siffrin et al. showed that specifically Th17 cells form immunosynapses with axons, leading to fast axonal damage. This pathway of neurotoxicity was unique as it was independent of MHCII-TCR interactions with the neurons. It was shown that Th17 cells elicited neurotoxicity by secretion of glutamate and that calcium flux in axons associated with Th17 cells was followed by axonal degeneration. The pathway of axonal damage and recognition of neurons remains to be discovered.

$\mathrm{T}$ helper cells can probably also harm the CNS cells directly by their cytokines, as it was shown in culture that both IFN- $\gamma$ and TNF can directly kill oligodendrocytes (ODCs). ${ }^{[13-116]}$ Since ODCs, the myelin-producing cells of the CNS, do not express or upregulate MHC class II in inflammation, the damage by cytokines in the CNS could occur as a side effect. This occurs when T cells are activated by monocyte-derived macrophages/DCs in the CNS which present myelin antigen on MHC class II molecules. In vivo, the role of direct damage by cytokines versus indirect damage is hard to distinguish since the same cytokines also activate macrophages. The usage of conditional cytokine receptor knockout mice should demonstrate inasmuch their ligands have direct effects on ODCs or neurons in vivo.

\section{$\mathrm{CD8}^{+} \mathrm{T}$ cells in EAE?}

$\mathrm{CD}^{+} \mathrm{T}$ cells are equipped with a very efficient cytotoxic killing mechanism containing perforin and granzymes, which they use to kill virus-infected cells. Granzymes are serine proteases, which are released into the cytosol of target cells with the help of perforin, a $\mathrm{Ca}^{2+}$-dependent pore-forming protein. ${ }^{[117,118]}$ Inside the cytosol, the granzymes induce apoptosis by different mechanisms. ${ }^{[119,120]}$ Cytotoxic T cells are very interesting cell types in EAE since MHC class I expression can be found on activated ODCs. Therefore, $\mathrm{CD}^{+} \mathrm{T}$ cells are able to directly recognize myelin peptides presented by ODCs and kill the latter. Furthermore, $\mathrm{CD}^{+} \mathrm{T}$ cells may be important players in MS. ${ }^{[121,122]}$ 
As described above, the standard models of EAE induction, which use antigens emulsified in CFA, ${ }^{[123]}$ seem to be largely independent of $\mathrm{CD} 8^{+} \mathrm{T}$ cells. In line with this were findings with perforin knockout mice, which showed a higher disease score than controls. ${ }^{[124,125]}$ This pointed rather to a regulatory role of the perforin-granzyme pathway, maybe as part of Tregs or of $\mathrm{CD}^{+}$suppressor $\mathrm{T}$ cells in EAE. Nevertheless, some reports showed that myelin-specific $\mathrm{CD} 8^{+} \mathrm{T}$ cells, indeed, are able to induce EAE including demyelination. First, Joan Goverman's group described the MBP-derived peptide $\mathrm{MBP}_{79-87}$ presented by the MHC class I molecule $\mathrm{K}^{\mathrm{k}}$, which was able to induce $\mathrm{CD}^{+} \mathrm{T}$ cells in $\mathrm{MBP}$-deficient $\mathrm{C} 3 \mathrm{H}$-shiverer mice ${ }^{[126]}$ In vitro-activated $\mathrm{CD} 8^{+} \mathrm{T}$ cell clones against this epitope, which were isolated from immunized WT $\mathrm{C} 3 \mathrm{H}$ mice, were able to transfer EAE with severe demyelination with a majority of lesions in brain parenchyma. ${ }^{[127]} \mathrm{Al}-$ though signs of major cytotoxic damage were visible in this model, the role of perforin or granzymes was not investigated; but a role for IFN- $\gamma$ was demonstrated in this model. Another group also reported that MOG-specific CD8 ${ }^{+} \mathrm{T}$ cells, in vitro-expanded from mice immunized against $\mathrm{MOG}_{35-55}$, are able to transfer EAE with demyelination. ${ }^{[128]}$ The mechanism of pathology by these transferred $\mathrm{CD}^{+} \mathrm{T}$ cells was not investigated. Apparently, $\mathrm{MOG}_{35-55}$ contains nested epitopes, $\mathrm{MOG}_{37-46}$ and $\mathrm{MOG}_{44-54}$, which can be presented by the MHC class I molecule $\mathrm{D}^{\mathrm{b}}$ and are able to stimulate $\mathrm{CD}^{+} \mathrm{T}$ cells. ${ }^{[129,130]}$ Apparently, these cells do not seem to play an important role in primary immunizations, but can grow out from in vitro cultures under IL-2 stimulation. More recently, Huber et al. described the presence of CD8 ${ }^{+} \mathrm{T}$ cells expressing IL-17A, so-called Tc17 cells, in lymph nodes and in the inflamed CNS of EAE animals

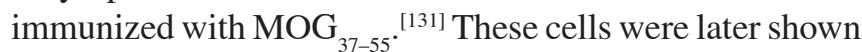
to play a supportive function for Th17 cells in EAE. ${ }^{[132]}$ In their system, Tc17 cells needed to express IL-17A to render transferred $\mathrm{CD}^{+}{ }^{+} \mathrm{T}$ cells pathogenic. Surprisingly, pathogenicity of the transferred $\mathrm{CD} 4^{+} \mathrm{T}$ cells was independent of their own expression of IL-17A.

In addition, several CD8-based TCR transgenic models for CNS inflammation were developed by different groups. Two groups created mice expressing neo-antigens in ODCs. $\mathrm{Na}$ et al. expressed ovalbumin (OVA) cytosolically in ODCs and found a very early fulminant demyelinating CNS inflammation in double-transgenic animals co-expressing the OT-1 transgenic TCR. ${ }^{[133,134]}$ Also, this group did not investigate inasmuch the perforin-granzyme pathway was implicated in disease. Like in the C3H MBP system by Goverman's group, they found that IFN- $\gamma$ played an important role in pathogenicity, probably via activation of ODCs through upregulation of MHC class I and co-stimulatory molecules. The group of Lennart Mars crossed hemagglutinin (HA)-specific
TCR transgenic CL4-TCR mice with mice expressing HA in ODCs. ${ }^{[135]}$ In this model, a role for perforin-granzyme mediated killing of ODCs was suggested, as $\mathrm{CD} 8^{+} \mathrm{T}$ cells containing polarized granzyme-filled vesicles in direct contact with ODCs were found. Recently, Cabarrocas et al. reported a new $\mathrm{CD}^{+} \mathrm{TCR}$ transgenic mouse (BG1 TCR) recognizing the astrocyte-specific glial fibrillary acidic protein (GFAP) peptide 264-274 presented by $\mathrm{K}^{\mathrm{b}}$. Upon activation of these adoptively transferred cells by infection with recombinant GFAP-expressing viruses, EAE scores developed with infiltrating $\mathrm{CD}^{+} \mathrm{T}$ cells expressing high levels of granzyme B and IFN- $\gamma^{[136]}$

Although several CD8 ${ }^{+} \mathrm{T}$ cell-mediated EAE models have been developed, the detailed molecular mechanisms of pathology by these cells have not yet been clarified. Open questions include the role of perforin and whether granzymes and specifically which granzymes play a role in pathology and which proteins in ODCs or neurons are targets of the proteases in $\mathrm{CD} 8^{+} \mathrm{T}$ cell-mediated EAE. Though the common molecule needed, as opposed to EAE mediated by $\mathrm{CD}^{+} \mathrm{T}$ cells, is IFN- $\gamma$ Its major function may be to upregulate MHC class I on target tissue cells for recognition of cytotoxic $\mathrm{T}$ cells.

\section{Conclusion}

Very distinct EAE models were developed in the past years. These models show different characteristics in disease phenotype, histopathology, and their cellular and molecular players, and thereby do reflect distinct features of MS. T cells in these different models come with different flavors and may use different molecules to interact and communicate with other cells and to direct pathological events. Therefore, certain molecular pathways are important in one model, but negligible or redundant in the other. Major non-redundant cytokines in basically all the models are IL-23, GM-CSF, and IL-6, whereas the role of IL-17 and IFN- $\gamma$ may be pleiotropic and model-specific.

\section{Acknowledgement}

The author wants to thank Ari Waisman, Sonja Moos, and Khalad Karram for critical reading and corrections. This work was funded by TR128 TPA3 to the author.

\section{REFERENCES}

1. Rivers TM, Sprunt DH, Berry GP. Observations on attempts to produce acute encephalomyelitis in monkeys. J Exp Med 1933;58:39-53.

2. Ben-Nun A, Wekerle H, Cohen IR. The rapid isolation of clonable antigen-specific $\mathrm{T}$ lymphocyte lines capable of mediating autoimmune encephalomyelitis. Eur J Immunol 1981;11:195-9.

3. Zamvil SS, Mitchell DJ, Moore AC, Kitamura K, Steinman L, 
Rothbard JB. T-cell epitope of the autoantigen myelin basic protein that induces encephalomyelitis. Nature 1986;324:258-60.

4. Ben-Nun A, Wekerle H, Cohen IR. Vaccination against autoimmune encephalomyelitis with T-lymphocyte line cells reactive against myelin basic protein. Nature 1981;292:60-1.

5. Zamvil S, Nelson P, Trotter J, Mitchell D, Knobler R, Fritz R, et al. T-cell clones specific for myelin basic protein induce chronic relapsing paralysis and demyelination. Nature 1985;317:355-8.

6. Serafini B, Muzio L, Rosicarelli B, Aloisi F. Radioactive in situ hybridization for Epstein-Barr virus-encoded small RNA supports presence of Epstein-Barr virus in the multiple sclerosis brain. Brain 2013;136:e233.

7. Serafini B, Rosicarelli B, Franciotta D, Magliozzi R, Reynolds R, Cinque P, et al. Dysregulated Epstein-Barr virus infection in the multiple sclerosis brain. J Exp Med 2007;204:2899-912.

8. Kurschus FC, Wörtge S, Waisman A. Modeling a complex disease: Multiple sclerosis. Adv Immunol 2011;110:111-37.

9. Barnett MH, Prineas JW. Relapsing and remitting multiple sclerosis: Pathology of the newly forming lesion. Ann Neurol 2004;55:458-68.

10. Lucchinetti CF, Brück W, Rodriguez M, Lassmann H. Distinct patterns of multiple sclerosis pathology indicates heterogeneity on pathogenesis. Brain Pathol 1996;6:259-74.

11. Lucchinetti C, Brück W, Parisi J, Scheithauer B, Rodriguez M, Lassmann H. Heterogeneity of multiple sclerosis lesions: Implications for the pathogenesis of demyelination. Ann Neurol 2000;47:707-17.

12. Barnett MH, Sutton I. The pathology of multiple sclerosis: A paradigm shift. Curr Opin Neurol 2006;19:242-7.

13. Babbe H, Roers A, Waisman A, Lassmann H, Goebels N Hohlfeld R, et al. Clonal expansions of CD $8(+) \mathrm{T}$ cells dominate the $\mathrm{T}$ cell infiltrate in active multiple sclerosis lesions as shown by micromanipulation and single cell polymerase chain reaction. J Exp Med 2000;192:393-404.

14. Wucherpfennig KW, Newcombe J, Li H, Keddy C, Cuzner ML, Hafler DA. T cell receptor V alpha-V beta repertoire and cytokine gene expression in active multiple sclerosis lesions. J Exp Med 1992;175:993-1002.

15. Koh DR, Fung-Leung WP, Ho A, Gray D, Acha-Orbea H, Mak TW. Less mortality but more relapses in experimental allergic encephalomyelitis in CD8-/- mice. Science 1992;256:1210-3.

16. Ransohoff RM, Brown MA. Innate immunity in the central nervous system. J Clin Invest 2012;122:1164-71.

17. Gonzalez-Navajas JM, Fine S, Law J, Datta SK, Nguyen KP, $\mathrm{Yu} \mathrm{M}$, et al. TLR4 signaling in effector CD4+T cells regulates TCR activation and experimental colitis in mice. J Clin Invest 2010;120:570-81.

18. Reynolds JM, Pappu BP, Peng J, Martinez GJ, Zhang Y, Chung Y, et al. Toll-like receptor 2 signaling in CD4(+) T lymphocytes promotes $\mathrm{T}$ helper 17 responses and regulates the pathogenesis of autoimmune disease. Immunity 2010;32:692-702.

19. Stromnes IM, Cerretti LM, Liggitt D, Harris RA, Goverman JM. Differential regulation of central nervous system autoimmunity by T (H) 1 and T (H) 17 cells. Nat Med 2008;14:337-42.

20. Mosmann TR, Cherwinski H, Bond MW, Giedlin MA, Coffman RL. Two types of murine helper T cell clone. I. Definition according to profiles of lymphokine activities and secreted proteins. J Immunol
$1986 ; 136: 2348-57$

21. Renno T, Zeine R, Girard JM, Gillani S, Dodelet V, Owens T. Selective enrichment of Th1 CD45RBlow CD4+T cells in autoimmune infiltrates in experimental allergic encephalomyelitis. Int Immunol 1994;6:347-54.

22. Ando DG, Clayton J, Kono D, Urban JL, Sercarz EE. Encephalitogenic T cells in the B10.PL model of experimental allergic encephalomyelitis (EAE) are of the Th-1 lymphokine subtype. Cell Immunol 1989;124:132-43.

23. Lafaille JJ, Keere FV, Hsu AL, Baron JL, Haas W, Raine CS, et al. Myelin basic protein-specific Thelper 2 (Th2) cells cause experimental autoimmune encephalomyelitis in immunodeficient hosts rather than protect them from the disease. J Exp Med 1997;186:307-12.

24. Ferber IA, Brocke S, Taylor-Edwards C, Ridgway W, Dinisco C, Steinman L, et al. Mice with a disrupted IFN-gamma gene are susceptible to the induction of experimental autoimmune encephalomyelitis (EAE). J Immunol 1996;156:5-7.

25. Willenborg DO, Fordham SA, Staykova MA, Ramshaw IA, Cowden WB. IFN-gamma is critical to the control of murine autoimmune encephalomyelitis and regulates both in the periphery and in the target tissue: A possible role for nitric oxide. J Immunol 1999;163:5278-86.

26. Becher B, Durell BG, Noelle RJ. Experimental autoimmune encephalitis and inflammation in the absence of interleukin-12. J Clin Invest 2002;110:493-7.

27. Gran B, Zhang GX, Yu S, Li J, Chen XH, Ventura ES, et al. IL-12p35-deficient mice are susceptible to experimental autoimmune encephalomyelitis: Evidence for redundancy in the IL-12 system in the induction of central nervous system autoimmune demyelination. J Immunol 2002;169:7104-10.

28. Zhang GX, Gran B, Yu S, Li J, Siglienti I, Chen X, et al. Induction of experimental autoimmune encephalomyelitis in IL-12 receptor-beta 2-deficient mice: IL-12 responsiveness is not required in the pathogenesis of inflammatory demyelination in the central nervous system. J Immunol 2003;170:2153-60.

29. Cua DJ, Sherlock J, Chen Y, Murphy CA, Joyce B, Seymour B, et al. Interleukin-23 rather than interleukin-12 is the critical cytokine for autoimmune inflammation of the brain. Nature 2003;421:744-8.

30. Langrish CL, Chen Y, Blumenschein WM, Mattson J, Basham B, Sedgwick JD, et al. IL-23 drives a pathogenic T cell population that induces autoimmune inflammation. J Exp Med 2005;201:233-40.

31. Becher B, Durell BG, Noelle RJ. IL-23 produced by CNS-resident cells controls $\mathrm{T}$ cell encephalitogenicity during the effector phase of experimental autoimmune encephalomyelitis. J Clin Invest 2003;112:1186-91.

32. Ivanov II, McKenzie BS, Zhou L, Tadokoro CE, Lepelley A, Lafaille JJ, et al. The orphan nuclear receptor RORgammat directs the differentiation program of proinflammatory IL-17+T helper cells. Cell 2006;126:1121-33

33. Yang XO, Pappu BP, Nurieva R, Akimzhanov A, Kang HS, Chung Y, et al. Thelper 17 lineage differentiation is programmed by orphan nuclear receptors ROR alpha and ROR gamma. Immunity 2008;28:29-39.

34. Kurschus FC, Croxford AL, Heinen AP, Wörtge S, Ielo D, Waisman A. Genetic proof for the transient nature of the Th17 phenotype. Eur J Immunol 2010;40:3336-46.

35. Hirota K, Duarte JH, Veldhoen M, Hornsby E, Li Y, Cua DJ, et al. Fate mapping of IL-17-producing T cells in inflammatory responses. Nat Immunol 2011;12:255-63. 
36. Yang Y, Weiner J, Liu Y, Smith AJ, Huss DJ, Winger R, et al. T-bet is essential for encephalitogenicity of both Th1 and Th17 cells. J Exp Med 2009;206:1549-64.

37. Lee YK, Turner H, Maynard CL, Oliver JR, Chen D, Elson CO, et al. Late developmental plasticity in the $\mathrm{T}$ helper 17 lineage. Immunity 2009;30:92-107.

38. Chu CQ, Wittmer S, Dalton DK. Failure to suppress the expansion of the activated CD4 $\mathrm{T}$ cell population in interferon gamma-deficient mice leads to exacerbation of experimental autoimmune encephalomyelitis. J Exp Med 2000;192:123-8.

39. Masters SL, Mielke LA, Cornish AL, Sutton CE, O’Donnell J, Cengia LH, et al. Regulation of interleukin-1beta by interferon-gamma is species specific, limited by suppressor of cytokine signalling 1 and influences interleukin-17 production. EMBO Rep 2010;11:640-6.

40. Wang Z, Hong J, Sun W, Xu G, Li N, Chen X, et al. Role of IFN-gamma in induction of Foxp3 and conversion of CD4+CD25-T cells to CD4+Tregs. J Clin Invest 2006;116:2434-41.

41. Yasui H, Takai K, Yoshida R, Hayaishi O. Interferon enhances tryptophan metabolism by inducing pulmonary indoleamine 2,3-dioxygenase: Its possible occurrence in cancer patients. Proc Natl Acad Sci USA 1986;83:6622-6.

42. Loke P, Allison JP. PD-L1 and PD-L2 are differentially regulated by Th1 and Th2 cells. Proc Natl Acad Sci USA 2003;100:5336-41.

43. Codarri L, Gyulveszi G, Tosevski V, Hesske L, Fontana A, Magnenat $\mathrm{L}$, et al. RORgammat drives production of the cytokine GM-CSF in helper T cells, which is essential for the effector phase of autoimmune neuroinflammation. Nat Immunol 2011;12:560-7.

44. Becher B, Durell BG, Miga AV, Hickey WF, Noelle RJ. The clinical course of experimental autoimmune encephalomyelitis and inflammation is controlled by the expression of CD40 within the central nervous system. J Exp Med 2001;193:967-74.

45. Gerritse K, Laman JD, Noelle RJ, Aruffo A, Ledbetter JA, Boersma WJ, et al. CD40-CD40 ligand interactions in experimental allergic encephalomyelitis and multiple sclerosis. Proc Natl Acad Sci USA 1996;93:2499-504.

46. Grewal IS, Foellmer HG, Grewal KD, Xu J, Hardardottir F, Baron JL, et al. Requirement for CD40 ligand in costimulation induction, $\mathrm{T}$ cell activation, and experimental allergic encephalomyelitis. Science 1996;273:1864-7.

47. Korn T, Reddy J, Gao W, Bettelli E, Awasthi A, Petersen TR, et al. Myelin-specific regulatory T cells accumulate in the CNS but fail to control autoimmune inflammation. Nat Med 2007;13:423-31.

48. Kolls JK, Linden A. Interleukin-17 family members and inflammation. Immunity 2004;21:467-76

49. Hymowitz SG, Filvaroff EH, Yin JP, Lee J, Cai L, Risser P, et al. IL-17s adopt a cystine knot fold: Structure and activity of a novel cytokine, IL-17F, and implications for receptor binding. EMBO J 2001;20:5332-41.

50. Awane M, Andres PG, Li DJ, Reinecker HC. NF-kappa B-inducing kinase is a common mediator of IL-17-, TNF-alpha-, and IL-1 beta-induced chemokine promoter activation in intestinal epithelial cells. J Immunol 1999;162:5337-44.

51. Chang SH, Park H, Dong C. Act1 adaptor protein is an immediate and essential signaling component of interleukin-17 receptor. J Biol Chem 2006;281:35603-7.

52. Zepp J, Wu L, Li X. IL-17 receptor signaling and Thelper 17-mediated autoimmune demyelinating disease. Trends Immunol 2011;32:232-9.

53. Iwakura $Y$, Ishigame $\mathrm{H}$, Saijo $\mathrm{S}$, Nakae $\mathrm{S}$. Functional specialization of interleukin-17 family members. Immunity 2011;34:149-62.

54. Ramirez-Carrozzi V, Sambandam A, Luis E, Lin Z, Jeet S, Lesch J, et al. IL-17C regulates the innate immune function of epithelial cells in an autocrine manner. Nat Immunol 2011;12:1159-66.

55. Johnston A, Fritz Y, Dawes SM, Diaconu D, Al-Attar PM, Guzman AM, et al. Keratinocyte overexpression of IL-17C promotes psoriasiform skin inflammation. J Immunol 2013;190:2252-62.

56. Yao Z, Painter SL, Fanslow WC, Ulrich D, Macduff BM, Spriggs MK, et al. Human IL-17: A novel cytokine derived from T cells. J Immunol 1995;155:5483-6.

57. Lockhart E, Green AM, Flynn JL. IL-17 production is dominated by gammadelta $\mathrm{T}$ cells rather than CD4 T cells during Mycobacterium tuberculosis infection. J Immunol 2006;177:4662-9.

58. Rachitskaya AV, Hansen AM, Horai R, Li Z, Villasmil R, Luger D, et al. Cutting edge: NKT cells constitutively express IL-23 receptor and RORgammat and rapidly produce IL-17 upon receptor ligation in an IL-6-independent fashion. J Immunol 2008;180:5167-71.

59. Takatori H, Kanno Y, Watford WT, Tato CM, Weiss G, Ivanov II, et al. Lymphoid tissue inducer-like cells are an innate source of IL-17 and IL-22. J Exp Med 2009;206:35-41.

60. Spits H, Artis D, Colonna M, Diefenbach A, Di Santo JP, Eberl G, et al. Innate lymphoid cells--a proposal for uniform nomenclature. Nat Rev Immunol 2013;13:145-9.

61. Hueber AJ, Asquith DL, Miller AM, Reilly J, Kerr S, Leipe J, et al. Mast cells express IL-17A in rheumatoid arthritis synovium. J Immunol 2010;184:3336-40.

62. Taylor PR, Roy S, Leal SM, Jr, Sun Y, Howell SJ, Cobb BA, et al. Activation of neutrophils by autocrine IL-17A-IL-17RC interactions during fungal infection is regulated by IL-6, IL-23, RORgammat and dectin-2. Nat Immunol 2014;15:143-51.

63. Ferretti S, Bonneau O, Dubois GR, Jones CE, Trifilieff A. IL-17, produced by lymphocytes and neutrophils, is necessary for lipopolysaccharide-induced airway neutrophilia: IL-15 as a possible trigger. J Immunol 2003;170:2106-12.

64. Li L, Huang L, Vergis AL, Ye H, Bajwa A, Narayan V, et al. IL-17 produced by neutrophils regulates IFN-gamma-mediated neutrophil migration in mouse kidney ischemia-reperfusion injury. J Clin Invest 2010;120:331-42.

65. Yao Z, Fanslow WC, Seldin MF, Rousseau AM, Painter SL, Comeau MR, et al. Herpesvirus Saimiri encodes a new cytokine, IL-17, which binds to a novel cytokine receptor. Immunity 1995;3:811-21.

66. Hu Y, Ota N, Peng I, Refino CJ, Danilenko DM, Caplazi P, et al IL-17RC is required for IL-17A- and IL-17F-dependent signaling and the pathogenesis of experimental autoimmune encephalomyelitis. J Immunol 2010;184:4307-16.

67. Toy D, Kugler D, Wolfson M, Vanden Bos T, Gurgel J, Derry J, et al. Cutting edge: interleukin 17 signals through a heteromeric receptor complex. J Immunol 2006;177:36-9.

68. Huppert J, Closhen D, Croxford A, White R, Kulig P, Pietrowski E, et al. Cellular mechanisms of IL-17-induced blood-brain barrier disruption. FASEB J 2010;24:1023-34.

69. Numasaki M, Fukushi J, Ono M, Narula SK, Zavodny PJ, Kudo T, 
et al. Interleukin-17 promotes angiogenesis and tumor growth. Blood 2003;101:2620-7.

70. Heidenreich R, Rocken M, Ghoreschi K. Angiogenesis drives psoriasis pathogenesis. Int J Exp Pathol 2009;90:232-48.

71. Pickens SR, Volin MV, Mandelin AM $2^{\text {nd }}$, Kolls JK, Pope RM, Shahrara S. IL-17 contributes to angiogenesis in rheumatoid arthritis. J Immunol 2010;184:3233-41.

72. El Malki K, Karbach SH, Huppert J, Zayoud M, Reissig S. Schuler R, et al. An alternative pathway of imiquimod-induced psoriasis-like skin inflammation in the absence of interleukin-17 receptor a signaling. J Invest Dermatol 2013;133:441-51.

73. Kroenke MA, Carlson TJ, Andjelkovic AV, Segal BM. IL-12- and IL-23-modulated T cells induce distinct types of EAE based on histology, CNS chemokine profile, and response to cytokine inhibition. J Exp Med 2008;205:1535-41.

74. Zehntner SP, Brickman C, Bourbonniere L, Remington L, Caruso M, Owens T. Neutrophils that infiltrate the central nervous system regulate T cell responses. J Immunol 2005;174:5124-31.

75. Soulika AM, Lee E, McCauley E, Miers L, Bannerman P, Pleasure D. Initiation and progression of axonopathy in experimental autoimmune encephalomyelitis. J Neurosci 2009;29:14965-79.

76. Carlson T, Kroenke M, Rao P, Lane TE, Segal B. The Th17-ELR+CXC chemokine pathway is essential for the development of central nervous system autoimmune disease. J Exp Med 2008;205:811-23.

77. McColl SR, Staykova MA, Wozniak A, Fordham S, Bruce J, Willenborg DO. Treatment with anti-granulocyte antibodies inhibits the effector phase of experimental autoimmune encephalomyelitis. J Immunol 1998;161:6421-6.

78. Aube B, Levesque SA, Pare A, Chamma E, Kebir H, Gorina R, et al. Neutrophils mediate blood-spinal cord barrier disruption in demyelinating neuroinflammatory diseases. J Immunol 2014;193:2438-54.

79. Steinbach K, Piedavent M, Bauer S, Neumann JT, Friese MA. Neutrophils amplify autoimmune central nervous system infiltrates by maturing local APCs. J Immunol 2013;191:4531-9.

80. Kang Z, Wang C, Zepp J, Wu L, Sun K, Zhao J, et al. Act1 mediates IL-17-induced EAE pathogenesis selectively in NG2+glial cells. Nat Neurosci 2013;16:1401-8.

81. Kreymborg K, Etzensperger R, Dumoutier L, Haak S, Rebollo A, Buch T, et al. IL-22 is expressed by Th17 cells in an IL-23-dependent fashion, but not required for the development of autoimmune encephalomyelitis. J Immunol 2007;179:8098-104.

82. Laaksonen H, Guerreiro-Cacais AO, Adzemovic MZ, Parsa R, Zeitelhofer M, Jagodic M, et al. The multiple sclerosis risk gene IL22RA2 contributes to a more severe murine autoimmune neuroinflammation. Genes Immun 2014;15:457-65.

83. Sawcer S, Hellenthal G, Pirinen M, Spencer CC, Patsopoulos NA, Moutsianas L, et al. Genetic risk and a primary role for cell-mediated immune mechanisms in multiple sclerosis. Nature 2011;476:214-9.

84. Beyeen AD, Adzemovic MZ, Ockinger J, Stridh P, Becanovic K, Laaksonen $\mathrm{H}$, et al. IL-22RA2 associates with multiple sclerosis and macrophage effector mechanisms in experimental neuroinflammation. J Immunol 2010;185:6883-90.

85. Gonzalez-Garcia I, Zhao Y, Ju S, Gu Q, Liu L, Kolls JK, et al. IL-17 signaling-independent central nervous system autoimmunity is negatively regulated by TGF-beta. J Immunol 2009;182:2665-71.

86. Haak S, Croxford AL, Kreymborg K, Heppner FL, Pouly S, Becher B, et al. IL-17A and IL-17F do not contribute vitally to autoimmune neuro-inflammation in mice. J Clin Invest 2009;119:61-9.

87. Yang Y, Winger R, Lee PW, Nuro-Gyina PK, Minc A, Larson M, et al. Impact of suppressing RORgammat in ameliorating central nervous system autoimmunity. Clin Exp Immunol 2015; 179:108-18

88. Xiao S, Yosef N, Yang J, Wang Y, Zhou L, Zhu C, et al. Small-molecule RORgammat antagonists inhibit $\mathrm{T}$ helper 17 cell transcriptional network by divergent mechanisms. Immunity 2014;40:477-89.

89. Huh JR, Leung MW, Huang P, Ryan DA, Krout MR, Malapaka RR, et al. Digoxin and its derivatives suppress TH17 cell differentiation by antagonizing RORgammat activity. Nature 2011;472:486-90.

90. Solt LA, Kumar N, Nuhant P, Wang Y, Lauer JL, Liu J, et al. Suppression of TH17 differentiation and autoimmunity by a synthetic ROR ligand. Nature 2011;472:491-4.

91. El-Behi M, Ciric B, Dai H, Yan Y, Cullimore M, Safavi F, et al. The encephalitogenicity of T $(\mathrm{H}) 17$ cells is dependent on IL-1- and IL-23-induced production of the cytokine GM-CSF. Nat Immunol 2011;12:568-75.

92. Greter M, Helft J, Chow A, Hashimoto D, Mortha A, Agudo-Cantero J, et al. GM-CSF controls nonlymphoid tissue dendritic cell homeostasis but is dispensable for the differentiation of inflammatory dendritic cells. Immunity 2012;36:1031-46.

93. Ko HJ, Brady JL, Ryg-Cornejo V, Hansen DS, Vremec D, Shortman K, et al. GM-CSF-responsive monocyte-derived dendritic cells are pivotal in Th17 pathogenesis. J Immunol 2014;192:2202-9.

94. Sonderegger I, Iezzi G, Maier R, Schmitz N, Kurrer M, Kopf M. GM-CSF mediates autoimmunity by enhancing IL-6-dependent Th17 cell development and survival. J Exp Med 2008;205:2281-94.

95. Eugster HP, Frei K, Kopf M, Lassmann H, Fontana A. IL-6-deficient mice resist myelin oligodendrocyte glycoprotein-induced autoimmune encephalomyelitis. Eur J Immunol 1998;28:2178-87.

96. Agrawal S, Anderson P, Durbeej M, van Rooijen N, Ivars F, Opdenakker G, et al. Dystroglycan is selectively cleaved at the parenchymal basement membrane at sites of leukocyte extravasation in experimental autoimmune encephalomyelitis. J Exp Med 2006;203:1007-19.

97. Honorat JA, Kinoshita M, Okuno T, Takata K, Koda T, Tada S, et al. Xanthine oxidase mediates axonal and myelin loss in a murine model of multiple sclerosis. PLoS One 2013;8:e71329.

98. van der Goes A, Brouwer J, Hoekstra K, Roos D, van den Berg TK, Dijkstra C. D., Reactive oxygen species are required for the phagocytosis of myelin by macrophages. J Neuroimmunol 1998;92:67-75.

99. Brück W, Porada P, Poser S, Rieckmann P, Hanefeld F, Kretzschmar HA, et al. Monocyte/macrophage differentiation in early multiple sclerosis lesions. Ann Neurol 1995;38:788-96.

100. Yamasaki R, Lu H, Butovsky O, Ohno N, Rietsch AM, Cialic R, et al. Differential roles of microglia and monocytes in the inflamed central nervous system. J Exp Med 2014;211:1533-49.

101. Goverman J, Woods A, Larson L, Weiner LP, Hood L, Zaller DM. Transgenic mice that express a myelin basic protein-specific $\mathrm{T}$ cell receptor develop spontaneous autoimmunity. Cell 1993;72:551-60. 
102. Lafaille JJ, Nagashima K, Katsuki M, Tonegawa S. High incidence of spontaneous autoimmune encephalomyelitis in immunodeficient anti-myelin basic protein $\mathrm{T}$ cell receptor transgenic mice. Cell 1994; 78:399-408.

103. Olivares-Villagomez D, Wang Y, Lafaille JJ. Regulatory CD4(+) T cells expressing endogenous $\mathrm{T}$ cell receptor chains protect myelin basic protein-specific transgenic mice from spontaneous autoimmune encephalomyelitis. J Exp Med 1998;188:1883-94.

104. Pöllinger B, Krishnamoorthy G, Berer K, Lassmann H, Bosl MR, Dunn R, et al. Spontaneous relapsing-remitting EAE in the SJL/J mouse: MOG-reactive transgenic $\mathrm{T}$ cells recruit endogenous MOG-specific B cells. J Exp Med 2009;206:1303-16.

105. Bettelli E, Pagany M, Weiner HL, Linington C, Sobel RA, Kuchroo VK. Myelin oligodendrocyte glycoprotein-specific T cell receptor transgenic mice develop spontaneous autoimmune optic neuritis. J Exp Med 2003;197:1073-81.

106. Litzenburger T, Fassler R, Bauer J, Lassmann H, Linington C, Wekerle $\mathrm{H}$, et al. B lymphocytes producing demyelinating autoantibodies: Development and function in gene-targeted transgenic mice. J Exp Med 1998;188:169-80.

107. Molnarfi N, Schulze-Topphoff U, Weber MS, Patarroyo JC, Prod'homme T, Varrin-Doyer M, et al. MHC class II-dependent B cell APC function is required for induction of CNS autoimmunity independent of myelin-specific antibodies. J Exp Med 2013;210:2921-37.

108. Bettelli E, Baeten D, Jager A, Sobel RA, Kuchroo VK. Myelin oligodendrocyte glycoprotein-specific $\mathrm{T}$ and $\mathrm{B}$ cells cooperate to induce a Devic-like disease in mice. J Clin Invest 2006;116:2393-402.

109. Krishnamoorthy G, Lassmann H, Wekerle H, Holz A. Spontaneous opticospinal encephalomyelitis in a double-transgenic mouse model of autoimmune $\mathrm{T}$ cell/B cell cooperation. J Clin Invest 2006; 116:2385-92.

110. Cross AH, Waubant E. MS and the B cell controversy. Biochim Biophys Acta 2011;1812:231-8.

111. Serafini B, Rosicarelli B, Magliozzi R, Stigliano E, Aloisi F. Detection of ectopic B-cell follicles with germinal centers in the meninges of patients with secondary progressive multiple sclerosis. Brain Pathol $2004 ; 14: 164-74$

112. Siffrin V, Radbruch H, Glumm R, Niesner R, Paterka M, Herz J, et al. In vivo imaging of partially reversible th 17 cell-induced neuronal dysfunction in the course of encephalomyelitis. Immunity 2010;33:424-36

113. Hisahara S, Takano R, Shoji S, Okano H, Miura M. Role of caspase-1 subfamily in cytotoxic cytokine-induced oligodendrocyte cell death. J Neural Transm Suppl 2000;58:135-42.

114. Andrews T, Zhang P, Bhat NR. TNFalpha potentiates IFNgamma-induced cell death in oligodendrocyte progenitors. J Neurosci Res 1998;54:574-83.

115. Popko B, Baerwald KD. Oligodendroglial response to the immune cytokine interferon gamma. Neurochem Res 1999;24:331-8.

116. Vartanian T, Li Y, Zhao M, Stefansson K. Interferon-gamma-induced oligodendrocyte cell death: Implications for the pathogenesis of multiple sclerosis. Mol Med 1995;1:732-43.

117. Kurschus FC, Bruno R, Fellows E, Falk CS, Jenne DE. Membrane receptors are not required to deliver granzyme B during killer cell attack. Blood 2005;105:2049-58.
118. Kurschus FC, Fellows E, Stegmann E, Jenne DE. Granzyme B delivery via perforin is restricted by size, but not by heparan sulfate-dependent endocytosis. Proc Natl Acad Sci USA 2008;105:13799-804.

119. Hoves S, Trapani JA, Voskoboinik I. The battlefield of perforin/ granzyme cell death pathways. J Leukoc Biol 2010;87:237-43.

120. Fellows E, Gil-Parrado S, Jenne DE, Kurschus FC. Natural killer cell-derived human granzyme $\mathrm{H}$ induces an alternative, caspase-independent cell-death program. Blood 2007;110:544-52.

121. Neumann H, Medana IM, Bauer J, Lassmann H. Cytotoxic T lymphocytes in autoimmune and degenerative CNS diseases. Trends Neurosci 2002;25:313-9.

122. Medana I, Martinic MA, Wekerle H, Neumann H. Transection of major histocompatibility complex class I-induced neurites by cytotoxic T lymphocytes. Am J Pathol 2001;159:809-15.

123. Steinman L. Myelin-specific CD8 T cells in the pathogenesis of experimental allergic encephalitis and multiple sclerosis. J Exp Med 2001;194:F27-30.

124. Malipiero U, Frei K, Spanaus KS, Agresti C, Lassmann H, Hahne M, et al. Myelin oligodendrocyte glycoprotein-induced autoimmune encephalomyelitis is chronic/relapsing in perforin knockout mice, but monophasic in Fas- and Fas ligand-deficient lpr and gld mice. Eur J Immunol 1997;27:3151-60.

125. Beeston T, Smith TR, Maricic I, Tang X, Kumar V. Involvement of IFN-gamma and perforin, but not Fas/FasL interactions in regulatory $\mathrm{T}$ cell-mediated suppression of experimental autoimmune encephalomyelitis. J Neuroimmunol 2010;229:91-7.

126. Huseby ES, Ohlen C, Goverman J. Cutting edge: Myelin basic protein-specific cytotoxic $\mathrm{T}$ cell tolerance is maintained in vivo by a single dominant epitope in H-2k mice. J Immunol 1999;163:1115-8.

127. Huseby ES, Liggitt D, Brabb T, Schnabel B, Ohlen C, Goverman J. A pathogenic role for myelin-specific $\mathrm{CD} 8(+) \mathrm{T}$ cells in a model for multiple sclerosis. J Exp Med 2001;194:669-76.

128. Sun D, Whitaker JN, Huang Z, Liu D, Coleclough C, Wekerle H, et al. Myelin antigen-specific CD8+T cells are encephalitogenic and produce severe disease in C57BL/6 mice. J Immunol 2001;166:7579-87.

129. Sun D, Zhang Y, Wei B, Peiper SC, Shao H, Kaplan HJ. Encephalitogenic activity of truncated myelin oligodendrocyte glycoprotein (MOG) peptides and their recognition by CD8+MOG-specific T cells on oligomeric MHC class I molecules. Int Immunol 2003;15:261-8.

130. Ford ML, Evavold BD. Specificity, magnitude, and kinetics of MOG-specific CD8+T cell responses during experimental autoimmune encephalomyelitis. Eur J Immunol 2005;35:76-85.

131. Huber M, Heink S, Grothe H, Guralnik A, Reinhard K, Elflein K, et al. A Th17-like developmental process leads to CD8(+) Tc17 cells with reduced cytotoxic activity. Eur J Immunol 2009;39:1716-25.

132. Huber M, Heink S, Pagenstecher A, Reinhard K, Ritter J, Visekruna A, et al. IL-17A secretion by CD8+ T cells supports Th17-mediated autoimmune encephalomyelitis. J Clin Invest 2013;123:247-60.

133. Cao Y, Toben C, Na SY, Stark K, Nitschke L, Peterson A, et al. Induction of experimental autoimmune encephalomyelitis in transgenic mice expressing ovalbumin in oligodendrocytes. Eur J Immunol 2006;36:207-15. 
134. Na SY, Cao Y, Toben C, Nitschke L, Stadelmann C, Gold R, et al. Naive CD8 T-cells initiate spontaneous autoimmunity to a sequestered model antigen of the central nervous system. Brain 2008;131:2353-65.

135. Saxena A, Bauer J, Scheikl T, Zappulla J, Audebert M, Desbois S, et al. Cutting edge: Multiple sclerosis-like lesions induced by effector CD8 T cells recognizing a sequestered antigen on oligodendrocytes. J Immunol 2008;181:1617-21.

136. Cabarrocas J, Bauer J, Piaggio E, Liblau R, Lassmann H. Effective and selective immune surveillance of the brain by MHC class I-restricted cytotoxic T lymphocytes. Eur J Immunol 2003;33:1174-82.

137. Owens T, Bechmann I, Engelhardt B. Perivascular spaces and the two steps to neuroinflammation. J Neuropathol Exp Neurol 2008;67:1113-21.

138. Wennstrom M, Janelidze S, Bay-Richter C, Minthon L, Brundin L. Pro-Inflammatory Cytokines Reduce the Proliferation of NG2 Cells and Increase Shedding of NG2 In Vivo and In Vitro. PLoS One 2014;9:e109387. 